\title{
Formas de lidar com o desemprego: possibilidades e limites de um projeto de atuação em psicologia social do trabalho
}

\author{
Anete Souza Farina ${ }^{1}$ e Tatiana Freitas Stockler das Neves ${ }^{2}$ \\ Centro de Psicologia Aplicada ao Trabalho do Instituto de Psicologia da Universidade de São Paulo
}

\begin{abstract}
O artigo apresenta um projeto-piloto de atuação junto a pessoas desempregadas, desenvolvido no Centro de Psicologia Aplicada ao Trabalho (CPAT) do IPUSP. Na primeira parte do artigo é feita uma breve apresentação do contexto de elaboração do projeto e são abordadas as concepções teóricas que nortearam a proposta. $\mathrm{Na}$ segunda parte do artigo, são trazidos: objetivos do projeto e caracterização do grupo; desenho metodológico; descrição e análise de cada encontro. O projeto-piloto foi voltado a mulheres e homens desempregados com mais de 24 anos de idade, moradores da região metropolitana de São Paulo, através de trabalho em grupo com 10 pessoas, totalizando sete encontros. A proposta teve como foco a constituição de um lugar de reflexão e troca de experiências entre os participantes tanto em relação ao desemprego (às diversas compreensões, repercussões e formas de lidar com a situação), como sobre suas trajetórias de vida e trabalho e as possibilidades e limites das táticas e estratégias pessoais e coletivas para geração de renda e trabalho.
\end{abstract}

Palavras-chave: Desemprego, Trajetórias de trabalho, Geração de renda, Grupos com desempregados, Psicologia social do trabalho.

Ways to deal with unemployment: possibilities and limits of an action project in social psychology of work

This essay aims to present a pilot project of action towards unemployed people, developed in the Center of Psychology Applied to Work of the Institute of Psychology of Universidade de São Paulo. In the first part of the article, it is done a brief presentation of the context of project elaboration and are approached the theoretical conceptions that guided the proposal. In the second part, are brought: project objectives and group characterization, methodological design, description, and analysis of each meeting. The pilot project was aimed to men and women unemployed aged over 24, living in the metropolitan region of São Paulo, through a group work with 10 people, summing seven meetings. This proposition aimed the constitution of a place for reflection and experience exchange among the participants not only about the unemployment, but also the repercussions and ways to deal with it and about their life and work trajectories and limits and possibilities and personal and social strategies for income and work generation.

Keywords: Unemployment, Work trajectories, Income generation, Groups with unemployed people, Social psychology of work.

Por esse pão pra comer, por esse chão pra dormir

A certidão pra nascer, e a concessão pra sorrir

Por me deixar respirar, por me deixar existir

Deus lhe pague...

Chico Buarque (trecho da música Deus lhe pague, 1971).

\footnotetext{
1 Doutora em psicologia social pelo Instituto de Psicologia da Universidade de São Paulo. Supervisora de estágios e pesquisadora do Centro de Psicologia Aplicada ao Trabalho (CPAT).

2 Psicóloga, pesquisadora e supervisora de estágios do Centro de Psicologia Aplicada ao Trabalho (CPAT). Pesquisadora do LABI-IPUSP e do NIME-USP.
} 


\section{Breve apresentação}

Dara abordar a proposta de atuação junto a um grupo de pessoas desempregadas é preciso, antes, falar brevemente do lugar no qual ela foi construída. Trata-se um de projeto-piloto delineado por um grupo de profissionais e de alunos vinculados ao Centro de Psicologia Aplicada ao Trabalho (CPAT) do Instituto de Psicologia da Universidade de São Paulo (IPUSP). ${ }^{3}$ Esse centro, criado em 85 , realiza pesquisas, atividades de extensão comunitária e formação de alunos de graduação em psicologia, focalizando em suas discussões temas do mundo do trabalho e os relacionados aos processos organizativos. Ao tratar desses temas, privilegia-se "a leitura da psicologia social e aproxima-se da psicologia política, da psicologia da saúde e da psicologia comunitária” (Centro de Psicologia Aplicada ao Trabalho, 2005).

A preocupação com a temática do desemprego veio, dentre outras razões, da força com que o fenômeno se estruturou no Brasil e, especificamente em São Paulo, em um contexto mundial de profundas mudanças políticas, econômicas e sociais no sistema capitalista de produção e as decorrentes transformações do mundo do trabalho (Antunes, 2001; Mattoso, 1994; Pochmann, 1997). O desemprego desde o início da década de 90 ampliou-se e tornou-se ainda mais complexo, espraiando-se por diferentes grupos sociais e tornando-se pauta da imprensa, de programas e plataformas políticos, de projetos sindicais, de estudos acadêmicos, com vozes e olhares distintos sobre o fenômeno, considerado por alguns como um problema inexistente, por outros como passageiro, por outros ainda como estrutural (Marques, 1996).

Especialmente a partir de convênios $^{4}$ estabelecidos com o Serviço de Aconselhamento Psicológico (SAP) do IPUSP, desde 1999, e com projetos públicos de inserção profissional da Prefeitura Municipal de São Paulo (PMSP), em 2003 e 2004, o CPAT elaborou diversas atividades, dentre elas, a formação de grupos com pessoas desempregadas, nesse caso específico, aquelas com mais de 40 anos, pertencentes a famílias com baixa renda e cadastradas no Programa São Paulo Inclui da PMSP na época.

Esses convênios foram marco importante para as discussões sobre questões relativas às políticas públicas de combate ao desemprego e sobre possibilidades e limites da atuação da psicologia, em especial da psicologia do trabalho, nesse campo. A partir dessa atividade, das possibilidades e das dificuldades encontradas, pôde ser elaborada outra proposta, ainda exploratória, de atuação com um grupo de pessoas desempregadas na região metropolitana de São Paulo da qual apresentamos alguns elementos teóricos a seguir.

\section{Desemprego: a instituição de uma realidade objetiva}

Tomando o desemprego como fenômeno estrutural, interessava-nos compreender as diversas e complexas facetas que o fenômeno assumia na vida e no cotidiano das pessoas desempregadas na região metropolitana de São Paulo. Para tanto foi necessário situar alguns aspectos relativos ao desemprego nessa região e suas especificidades.

Desde a década de 80 e especialmente a partir da década de 90, São Paulo foi marcada pela reestruturação econômica e produtiva, que acarretou, dentre outros efeitos, na

\footnotetext{
3 Contribuíram para o desenho deste projeto desde 2003: Allan R. Dias, Débora A. Audi, Fábio de Oliveira, Flavio Ribeiro, Guilherme G. Pogibin, Joari A. S. de Carvalho, Kátia Ackermann, Leny Sato, Marcelo A. Ribeiro, Mariana A. de Amaral e Tania M. F. de A. Silva.

4 Dentre os convênios, destacam-se especialmente as interlocuções e ações conjuntas com: Maria Luisa S. Schmidt (SAP), Guilherme Scandiucci, Nina Nazário, Paulo S. Gil e Patrícia Oliveira (Programa São Paulo Inclui).
} 
diminuição da atividade produtiva, no grande aumento dos índices de desemprego e, concomitantemente, na ampliação das relações precárias de trabalho e no aumento da inserção de trabalhadores no chamado mercado informal, além do agravamento das condições de vida da população (Cacciamali, 2000; Cunha \& Dedecca, 2000; Montagner \& Haga, 2003).

Nesse contexto, os setores do mercado formal, como as indústrias metalúrgicas e os serviços bancários - que haviam contratado grande número de trabalhadores até a década de 80 na região metropolitana de São Paulo - sofreram um drástico enxugamento de seus quadros funcionais (Alves, 2000; Jinkings, 1995). Além disso, o setor público iniciou a implementação de certas diretrizes da chamada "reforma do Estado", começando um processo de privatização de empresas públicas, de terceirização de vários setores e serviços e de repasse da responsabilidade de execução de políticas públicas às chamadas "organizações sociais" (OSs), diminuindo as contratações e modificando as relações de trabalho inclusive no próprio setor público, o que tomaria sua forma mais explícita especialmente no fim da década de 90 e no início dos anos 2000 (Antunes, 2001; Ministério do Planejamento, 1997).

Tal contexto conformava outra realidade de emprego e trabalho na região e novos contornos ao desemprego vivido pela população. Frente a um desemprego que se alargou para novos grupos sociais (como jovens da classe média com grau de escolaridade superior e homens assalariados) e se aprofundou ainda mais para grupos que já enfrentavam as repercussões da desigualdade social e da divisão sexual do trabalho (como as mulheres negras, cuja principal forma de subsistência se dava através de trabalhos precários), cabe perguntar: como esses grupos sociais passaram a se posicionar e a lidar com tal cenário? (Bruschini \& Lombardi, 2003; Pochmann et al., 2006; Prefeitura Municipal de São Paulo, 2004).

A leitura de certos estudos, que a partir de meados da década de 90 abordaram essa questão, aponta para a diversidade de ações visando geração de renda e trabalho e de formas de lidar com o desemprego. Observa-se a construção e o uso de redes sociais através das relações de ajuda entre amigos, vizinhos ou familiares, por meio da religião, através de espaços de encontro como o bar (no caso dos homens) etc. (Ackermann et al., 2005; Azevedo et al., 1998). Observa-se também a busca tanto por políticas públicas de geração de renda e trabalho, como por políticas de assistência social e por serviços de saúde (Mandelbaum, 2004; Pochmann, 2003; Sato \& Schmidt, 2004).

Há a procura por postos de trabalho em serviços de recolocação e em programas sindicais e há a busca pelo trabalho informal como modo de subsistência ou como alternativa ao mercado formal de trabalho (Batista, 2005; Salvitti et al., 1999). Há inclusive a participação em projetos comunitários, a realização de clubes de troca ou a formação de empreendimentos solidários que se apresentam como outras formas de organização do trabalho e de participação política (Singer, 1998; Singer \& Souza, 2000).

Há também a compra e a leitura de revistas e jornais impressos ou o assistir a programas de televisão que oferecem "dicas" de como abrir um negócio próprio ou de como conseguir um emprego, além da procura pelos mais diversos cursos de qualificação (Guimarães, 2003; Neves, 2006). E há ainda, dentre outros, a desistência de procurar emprego ou trabalho diante de inúmeras tentativas frustradas, o chamado desemprego por desalento (Seligmann-Silva, 1997).

Dessas formas de lidar com o desemprego, tomam destaque especialmente as chamadas redes sociais. No caso específico de São Paulo - em comparação, por exemplo, com outros grandes centros urbanos do mundo, como Paris e Tóquio -, as redes se conformam como principal forma de apoio e de enfrentamento do desemprego, segundo as representações de pessoas desempregadas entrevistadas em pesquisa comparativa realizada nas três metrópoles entre 2001 e 2004. No caso parisiense, o Estado é visto como responsável pelo combate ao desemprego e pela assistência aos desempregados, em contraposição a 
Tóquio, onde o principal caminho vislumbrado é a busca individual por um emprego (Guimarães, 2005).

Tais representações encontram-se atreladas às diferentes realidades vividas nessas metrópoles: os entrevistados de Tóquio eram pessoas que tinham tido longos e estáveis períodos como empregados assalariados (em um país com vínculos mais estáveis de emprego); em Paris os entrevistados vinham de uma situação regular como assalariados e, quando desempregadas, contavam com a proteção do Estado (em um país que principalmente até a década de 70 possuía uma sólida política de bem estar social). Já em São Paulo, os entrevistados tinham histórico de desemprego recorrente em suas trajetórias de trabalho - em um país, como outros na América Latina, que não chegou a ter um período de pleno emprego nem de ampla proteção social do Estado (Guimarães, 2005).

Diante dessa nossa realidade, como propor uma forma de atuação em psicologia social que abrigasse a diversidade e, ao mesmo tempo, considerasse o que é comum às pessoas desempregadas em São Paulo frente a uma realidade mundial de desemprego estrutural?

Foi perante esse desafio que se buscou construir no CPAT um projeto-piloto de atuação com um grupo de pessoas desempregadas. Tal desafio pôs em cena inclusive os diferentes lugares e papéis que as pessoas, no caso, as desempregadas, assumem em nossa sociedade e as mediações feitas por elas entre os aspectos macro-sociais do desemprego, seu cotidiano e suas experiências e apropriações individuais (Berger \& Lukmann,1985; Heller, 2000). Entraram em cena também as concepções sociais e individuais sobre trabalho e emprego, sejam as que equivalem trabalho e emprego na sociedade capitalista de produção, sejam aquelas que compreendem o trabalho como atividade humana de transformação do mundo e da natureza (Arendt, 2000; Castel, 1999; Jahoda, 1987; Marcuse, 1997).

\section{O projeto de atuação com pessoas desempregadas}

\section{Intenções do projeto}

A intenção deste projeto foi constituir um espaço de reflexão e de encontro entre pessoas que estão em situação de desemprego, com o objetivo de ampliar as discussões sobre trabalho, desemprego, geração de renda e incentivar a formação de redes sociais, como elementos importantes de suporte social junto a essas pessoas.

As redes sociais aparecem como uma aproximação entre os pares e, como apontado anteriormente, configuram-se no Brasil como uma importante forma de as pessoas lidarem com o desemprego, um certo modo de apoio e solidariedade, e como tática para gerar renda e trabalho (Guimarães \& Hirata, 2006; Lautier \& Pereira, 1994; Singer, 2002). Uma das funções das redes é permitir uma alteração do lugar social que o desemprego ocupa como instituição e, assim, constituir-se como certa forma de resistência social.

\section{Modos de fazer: caracterização do grupo e desenho metodológico}

Para este projeto foi constituído um grupo de pessoas desempregadas, composto por 8 homens e 2 mulheres com idades superiores a 24 anos $^{5}$. Seus níveis de escolaridade eram: básico ( 3 pessoas), médio ( 4 pessoas) e superior ( 3 pessoas). Todos eram moradores da grande

5 A idade foi um critério de seleção para a composição do grupo com a finalidade de contemplar pessoas que apresentassem algum histórico profissional, não focalizando, portanto, o primeiro emprego. 
São Paulo, parte nascida na própria cidade e parte de outras localidades: uma pessoa proveniente de outra cidade do Estado de São Paulo e outras de outros Estados (uma do sudeste, duas do nordeste e uma do sul). As mulheres eram solteiras e uma delas tinha um filho; dos homens, quatro eram casados, dois destes com filhos.

O grupo foi coordenado por duas profissionais com formação na área de psicologia social do trabalho, cujo papel inicial era a coordenação e mediação do grupo. Os participantes aderiram de forma voluntária ao projeto, o que permitiu maior espontaneidade ao processo. O tempo de duração adotado em cada encontro foi de duas horas e meia, durante sete encontros, realizados uma vez por semana.

A escolha pelo trabalho em grupo deu-se por se considerar esta uma forma privilegiada de troca de experiências, de histórias e de informações entre diferentes pessoas que vivem cotidianamente o desemprego. $O$ grupo assume também um papel, de certa forma, de acolhimento dos sofrimentos e das indagações vividos por cada pessoa que enfrenta essa situação, minimizando em parte o sentimento de solidão comumente experienciado por quem está desempregado, especialmente se o está por um longo período de tempo.

Embora o grupo possa apresentar diversidades tanto nos modos de lidar, como nos de compreender o fenômeno do desemprego, nossa proposta incluiu refletir e problematizar concepções e percepções que atrelam o desemprego a questões individuais, como, por exemplo, o desemprego supostamente causado por comportamentos inadequados ou por falta de conhecimentos, idéia que nega o desemprego estrutural e culpabiliza o trabalhador.

Dentre os sete encontros realizados com o grupo, o primeiro foi de apresentação mútua. Os encontros seguintes visaram contemplar as seguintes linhas de atuação: compreensões e repercussões do desemprego contemporâneo; percepções sobre o mundo do trabalho; rememoração das trajetórias de trabalho; identificação de diferentes táticas ou estratégias de geração de renda e trabalho; saberes e conhecimentos construídos no percurso de trabalho; discussão de projetos e de atividades possíveis para geração de renda e trabalho. A cada encontro foi feito o registro das discussões ocorridas em um grande papel (cartolina), como um instrumento para retomada posterior e síntese das discussões ocorridas a cada encontro.

A intenção ao longo dos encontros foi estabelecer uma região de interlocução entre participantes e proponentes, o que se constituiu como desafio, dado os jogos de saber-poder presentes nessa relação (Bordieu, 1994, 1997; Nunes, 2002; Oliveira, 2000; Santos, 1999). Por essa razão, optou-se por atividades que partissem dos conhecimentos de cada um dos participantes e das trocas possíveis entre eles, configurando um lugar de reflexão pessoal, conjunta e também de formação, em que eram trazidos e debatidos outros pontos de vista e saberes sobre as temáticas abordadas.

A estrutura dos encontros apresentados abaixo serve como um norte para o tipo de trabalho proposto, mas não deve ser tomada como algo fixo ou que possa ser repetido independentemente do contexto, das realidades locais e das características de cada grupo.

\section{Discussão: análise e interpretação}

\section{Primeiro encontro - apresentação mútua}

A partir de um convite aberto às pessoas interessadas em participar do grupo, foi realizado um encontro prévio visando: discutir os objetivos do projeto e as expectativas das 
pessoas ao procurarem o grupo; apresentar o projeto em linhas gerais; identificar demandas e confirmar o interesse individual em participar. A estratégia adotada para esse encontro foi a apresentação formal do projeto, o detalhamento e a discussão com os participantes sobre os futuros encontros, buscando minimizar as dúvidas sobre os propósitos do projeto e estabelecer um contrato ético. Esse foi um momento importante tanto para as pessoas conhecerem a proposta, como para se entrar em contato com a diversidade de expectativas em relação ao grupo.

O contato inicial permitiu identificar, por exemplo, a demanda por um emprego com carteira assinada. $\mathrm{O}$ registro em carteira apareceu para grande parte dos participantes como possibilidade de uma renda mais estável do que os "bicos" ou o trabalho autônomo, de acesso a crediário em lojas, de acesso a direitos como aposentadoria, seguro-saúde e seguroacidentário, além de simbolizar marcas de dignidade e sinais de distinção. Supomos que haja relação com uma expectativa que parece ser comum a quem vive essa situação, que é muitas vezes a de encontrar um emprego com carteira assinada, pelo valor que ele tem em nossa sociedade tanto do ponto de vista simbólico, como material.

Nesse primeiro momento, as dúvidas ou apontamentos dos participantes convergiram para questionamentos sobre o projeto em si: se não se trataria de um teste ou de algum tipo de entrevista ou avaliação não explicitados aos participantes.

Essa tensão do que pode estar em jogo quando se propõe um tipo de projeto como este - distante em parte das práticas mais comuns de psicólogos que tratam dessas questões do emprego e do trabalho - pode ser também um exemplo das representações construídas e legitimadas pela psicologia organizacional. As práticas hegemônicas da psicologia no campo do trabalho e das organizações no Brasil têm sido as de recrutamento, seleção e treinamento de pessoal e isso marca também o imaginário das pessoas acerca do que pode acontecer em um grupo organizado por psicólogos num projeto voltado a trabalhadores, sejam desempregados ou não.

A esse respeito, há outro aspecto relevante a se considerar: muitos dos participantes já haviam se submetido a diversos processos seletivos em que não tiveram as informações adequadas sobre as atividades que deveriam executar no processo de avaliação, tendo de fazer algo cuja intenção não foi revelada. Tais experiências parecem marcar, de certo modo, parte das expectativas e dúvidas que os participantes apresentaram no momento inicial do grupo.

Houve também questionamentos sobre se o projeto iria ou não abrir novas oportunidades de trabalho para os participantes e expectativas de se quebrar certos "círculos viciosos" de respostas frente ao desemprego. Um dos participantes, ainda, disse buscar no grupo formas de "digerir certos sapos" encarados no mercado de trabalho e outro apontou os riscos de uma má orientação em relação a como enfrentar o desemprego.

\section{Segundo encontro - compreensões e repercussões do desemprego}

O segundo encontro visou compreender as percepções e as informações que os participantes tinham sobre o atual desemprego e realizar um debate com eles contextualizando o fenômeno do desemprego contemporâneo.

Para estimular as discussões foram utilizadas tiras de jornal impresso desenhadas por cartunistas (quadrinhos) em que, através da sátira e de ironias, apresentavam-se de forma crítica aspectos e questões relativas ao desemprego e ao mundo do trabalho atual, tais como mercado de trabalho e processos de seleção, abordando cenas e situações comumente enfrentadas por aqueles que estão desempregados. 
Em seus comentários, geralmente os participantes trouxeram reflexões tanto sobre as situações retratadas nos quadrinhos, como as vividas por eles em seu cotidiano. Os quadrinhos funcionaram, desse modo, como mote para começar a discussão, permitindo uma imersão no tema e desinibição dos participantes, devido ao caráter de humor apresentado pelas cenas. Tal discussão, por sua vez, pôde abrir alguns temas: como pensam o desemprego, como se vêem e como são vistos nessa situação por outros, quais as repercussões do desemprego enfrentadas.

Como apontado anteriormente, é preciso cuidado para não tornar os vários entendimentos, explicações e interpretações como um corpo único, mas sim considerar ainda contradições, paradoxos e heterogeneidades. O desafio aqui é a tensão entre olhares singulares e os pontos de vista comuns e o modo como tais compreensões e horizontes articulam-se em direção a determinadas ações ou outras formas de lidar com o desemprego.

A experiência desse encontro apontou para a existência de explicações tanto de caráter individual (que atribuem o desemprego à falta de qualificação, a características ou trajetórias pessoais), como de caráter macro-social (relativas à reestruturação produtiva, às políticas econômicas etc.), delineando assim o caráter polissêmico e polifônico do desemprego.

Em comum, reapareceu, como no primeiro encontro, a importância da carteira assinada e do emprego formal. Sobre as formas de lidar com a situação, ao mesmo tempo em que gostariam de estar empregados e tentaram se inserir no mercado formal por diversas vezes, sem sucesso, parte dos integrantes do grupo tinha alguma renda proveniente de trabalhos informais: trabalhos eventuais de jardinagem, pintura, montagem de máquinas, marcenaria, trabalho como secretária, venda de porta em porta de produtos de beleza ou de chocolates.

O trabalho informal feito por eles era visto como algo passageiro, as atividades realizadas não eram vistas como trabalho e tampouco havia o reconhecimento dos saberes adquiridos nesses fazeres. Os participantes consideravam-se atualmente desempregados e relataram que permaneciam em tais atividades como uma forma provisória de geração de renda até conseguirem um emprego formal.

Cabe ainda ressaltar que a diversidade de compreensões do desemprego nesse encontro ampliaram a percepção e alteraram alguns posicionamentos dos participantes acerca do tema e de outros aspectos do mundo do trabalho. Um exemplo foi o relato de participantes que haviam concluído o ensino superior e que, apesar disso, estavam desempregados há mais de um ano (não eram recém-formados). Esse relato ajudou a problematizar a compreensão trazida por outros participantes que se consideravam desempregados devido à falta de qualificação.

Como questões relativas às repercussões do desemprego, foram apontados: o aceitar ou não todo tipo de trabalho quando se está desempregado por muito tempo; o medo e a necessidade de "dar a cara para bater" na busca de trabalho; o cansaço e a desesperança, por vezes, nessa busca devidos às várias tentativas frustradas; o desejo de sentir-se valorizado através de um trabalho; a tensão existente entre um certo apoio familiar ou de amigos e os olhares preconceituosos de outras pessoas; enfim, a questão de estarem entre a busca de reconhecimento social pelo que podem e gostariam de fazer como trabalho e o sofrimento proveniente da pressão social por estarem desempregados. 


\section{Terceiro encontro - percepções sobre o mundo do trabalho}

Nesse encontro, o objetivo foi conhecer e discutir as percepções sobre o mundo do trabalho e as ocupações, deslocando o foco do desemprego e considerando as interpretações sobre emprego, trabalho, "bico", trabalho doméstico, dentre outras designações.

Um recurso utilizado para isso foi a fotografia. A partir de fotos de diversas pessoas em situações de trabalho (trabalho doméstico, na construção civil, em fábrica, em escritório, artístico, como vendedor ambulante), buscou-se apreender as percepções e representações sobre esses trabalhos, sobre como são valorados, se são ou não considerados trabalhos, com quais se tem afinidade ou não e, a partir disso, problematizar estereótipos e preconceitos em relação a certos trabalhos.

A respeito da valoração dos tipos de trabalhos, destacaram-se como os mais valorizados pelos participantes e socialmente o trabalho na fábrica ou no escritório; já os trabalhos vistos como mais penosos e menos reconhecidos socialmente foram o trabalho doméstico e o da construção civil. $O$ trabalho artístico apresentou-se para eles como o de maior liberdade para a criação, em contraposição aos demais trabalhos, porém, como um trabalho em que poucas vezes se tem uma remuneração adequada ou suficiente para se viver.

As reflexões a respeito do trabalho artístico derivaram para discussões sobre as possibilidades e impossibilidades de se ter realização pessoal em um trabalho. Uns acreditavam ser possível encontrar alguma forma de realização e prazer nos mais diversos trabalhos e outros consideravam que isso se restringia a trabalhos artísticos ou artesanais.

Outros temas decorrentes foram: as diferenças entre um trabalho repetitivo e um trabalho mais artesanal, este último visto como o que teria maior possibilidade para a criação; e as diversas formas de aprendizagem relativas ao trabalho, desde cursos mais padronizados (como cursos de vendas) até formas de aprendizado de um ofício que se passa de pai para filho (por exemplo, na construção pela população de açudes na região Nordeste).

O trabalho do vendedor ambulante (camelô) foi descrito de modo ambíguo, ora como "bico" (atividade vista como temporária ou passageira para gerar renda, mas que não se configuraria como trabalho), ora como trabalho. Ora considerado como negativo por ser instável, ora positivado como algo que permitiria certa liberdade, nesses casos situando o trabalho do camelô em contraposição ao emprego formal.

Interessante notar nesse encontro como havia um olhar ambíguo em relação ao que era considerado trabalho e ao que era considerado desemprego. Por vezes, o desemprego era olhado como falta de emprego, outras vezes como falta de uma atividade remunerada. Relevante apontar que os participantes também relataram, como no segundo encontro, os olhares de outros sobre eles e a cobrança social que sofriam por não estarem trabalhando, chegando a serem vistos por vezes de modo preconceituoso, como "vagabundos".

\section{Quarto encontro - rememoração das trajetórias de trabalho}

No quarto encontro, propôs-se um exercício de rememoração das trajetórias de trabalho de cada participante. A rememoração é um exercício, ao mesmo tempo, de síntese e de retomada do que foi vivido e experienciado e pode abrir para novas significações das vivências e das experiências. Ela traz tanto aspectos pessoais, como sociais e se dá, nesse espaço, entre quem fala e quem ouve, não sendo nem um nem outro neutros em relação ao que é trazido e produzido naquele momento (Bosi, 2003; Schmidt, 1995).

Uma atividade proposta para possibilitar a rememoração foi que eles se dividissem em duplas ou trios e contassem uns para os outros um pouco sobre suas histórias de trabalho, para depois trazerem aspectos dessa conversa para o grupo todo. 
Pretendeu-se nesse encontro contemplar fragmentos das diferentes trajetórias de trabalho, suas singularidades e o que lhes é comum, considerando questões de gênero, referências de classe, grupos étnicos, condições sociais e econômicas, diversidades culturais. Buscou-se, ainda, a partir da rememoração, que eles trouxessem e refletissem inclusive sobre táticas utilizadas para superação de situações por eles consideradas como difíceis e também, através do resgate da trajetória, conversar sobre conhecimentos e práticas construídos por eles nos diferentes trabalhos realizados ao longo da vida.

A rememoração teve grande importância por permitir que os participantes retomassem a própria história de trabalho, os diferentes contextos do mundo do trabalho em que viveram, as diversas táticas utilizadas nesse percurso. Segundo vários dos participantes, há muito tempo não pensavam sobre seus trajetos, sobre os diferentes trabalhos que já haviam realizado e que tal relembrar foi uma forma de retomar esse caminho, dar-lhe novos significados, diminuindo em parte o sentimento de incapacidade.

Trouxeram relatos de trabalhos ou atividades que exerceram quando jovens, como: organização de festas, vendas de roupas ou realização de atividades esportivas durante a faculdade (entre os que tinham feito curso superior); ter sido office-boy, ter vendido produtos alimentícios pelo bairro onde morava, ter trabalhado com os pais (entre os que tinham cursado até o ensino médio); ter começado a trabalhar muito cedo, mas com registro em carteira, em postos de trabalho como servente de obra ou como operário de fábrica metalúrgica (entre os que tinham cursado até o fundamental). Apontaram, assim, certas diferenças de classe em relação aos tipos de trabalho feitos na juventude.

Dos trabalhos mais recentes, os que tinham até o primeiro grau trabalharam em tinturaria, gráfica ou metalúrgica (como operários); os que tinham segundo grau, em bares (como barman), em hospitais (como auxiliar de enfermagem), em setores administrativos de empresas ou em negócio próprio no ramo de alimentação; os que tinham feito o terceiro grau completo atuaram em administração de empresa, marketing ou na área de alimentos. Tratavase, portanto, de pessoas que em algum momento de suas vidas já tinham sido assalariadas (a maioria) ou já haviam tido um negócio próprio.

Em comum, ao contarem sobre os trabalhos realizados na vida adulta, todos trouxeram histórias também de exploração, submissão e humilhação no trabalho. A partir desses relatos, realizaram reflexões a respeito do fato de terem tentado suportar essas condições para permanecerem no emprego, o que não os impediu de serem demitidos.

De modo geral, nesse encontro, o rememorar e o compartilhar com os outros suas histórias possibilitou, em parte, ampliar a percepção de si mesmos, também como sujeitos sociais e históricos. A retomada das referências e dos papéis que tiveram em seus diversos trabalhos recompôs uma parte esmaecida de suas próprias histórias e abriu para reflexões sobre as condições e as relações de trabalho.

\section{Quinto encontro - identificação de diferentes táticas ou estratégias de geração de renda e trabalho}

No quinto encontro, a intenção foi de conhecer as táticas e as estratégias utilizadas pelos participantes para gerar renda e trabalho. A retomada da trajetória de trabalho, feita no encontro anterior, muitas vezes propiciou um solo fértil para essa discussão.

A proposta foi, em um primeiro momento, que eles se organizassem em pequenos grupos e contassem uns aos outros como faziam até ali para lidar com o desemprego, quais as saídas encontradas para gerar renda e as dificuldades enfrentadas nesse enfrentamento; que eles pudessem relatar também, se fosse o caso, histórias de outras pessoas que já haviam vivido essa situação e como elas fizeram para lidar com o desemprego e gerar renda ou obter 
trabalho. Após isso, cada pequeno grupo fez uma síntese dessas histórias e apresentou-as aos demais.

Partiu-se, assim, das experiências e histórias trazidas pelos participantes para que se estabelecesse a troca de experiências e de saberes e, com isso, ampliar-se o conhecimento que construíram sobre diferentes formas de trabalho e modos de gerar renda, para além do emprego e da carteira assinada, visando o reconhecimento de certas táticas ou estratégias que utilizariam para tanto.

Por táticas, compreendem-se as ações de pessoas desempregadas para gerarem alguma renda e, assim, sobreviverem, ações que são sempre provisórias e possíveis de acontecer momentaneamente em um determinado espaço social. São, por exemplo, os "bicos", arranjados a cada dia para garantir uma mínima subsistência. Já por estratégias entendem-se as ações planejadas no tempo, com uma certa distância, que permitem traçar os diversos aspectos que compõem o campo do mundo do trabalho atualmente e as características do desemprego contemporâneo, possibilitando um projeto de ações necessárias para, por exemplo, atingir o objetivo de conseguir um trabalho.

As táticas são como "raios, relâmpagos, fendas e achados no reticulado do sistema". As estratégias pressupõem um poder no espaço social que permite análise e planejamento para desenhar e executar determinadas ações (Certeau, 1999, p. 101). Nesse sentido, dependendo das condições (materiais e simbólicas) e das configurações sociais, as ações em direção ao mundo do trabalho se darão como táticas ou como estratégias.

No caso dos participantes do grupo, os que vinham de uma classe média mais bem estabelecida economicamente tiveram em algum momento de seu percurso de vida e de trabalho a possibilidade de desenhar certas estratégias que permitiram a participação no mercado de trabalho. Como exemplos, estudar em universidades públicas para garantir certas qualificações exigidas ou juntar o dinheiro de vários trabalhos e fazer cursos específicos para abrir um negócio próprio levando em conta os chamados "nichos" de mercado.

Muitos dos participantes, contudo, trouxeram relatos de buscas que foram se dando passo a passo, ocasionalmente, como serem chamados eventualmente para um trabalho temporário, por exemplo. Porém, com a reconfiguração do mundo do trabalho e do próprio sistema capitalista de produção, tanto aqueles que um dia puderam desenhar tais estratégias de trabalho, como aqueles que nunca o haviam feito encontravam-se, no momento em que o grupo ocorreu, em situações semelhantes e agindo, quando possível, apenas taticamente.

No grupo realizado, trouxeram como táticas para lidar com o desemprego ou gerar renda: realização de "bicos"; busca por cursos de qualificação e aperfeiçoamento; tentativa de montar negócio próprio; trabalho em negócio familiar; prestar concursos públicos; busca por informações sobre oportunidades de emprego em jornais impressos ou com amigos, familiares ou vizinhos; busca pela internet (no caso dos que podiam acessá-la); distribuição de currículos de porta em porta em fábricas ou lojas; realização de trabalhos voluntários.

As redes familiares (esposas, irmãos, pais, filhos) apareceram de modo relevante para quase todos os participantes, seja como apoio afetivo, seja como ajuda material para sobrevivência. Apenas no caso de um dos participantes a relação que a família estabeleceu com ele foi na direção oposta, marcada por preconceito e desqualificação. Em poucos casos foi trazida, ainda, a busca por atendimento psicológico ou psiquiátrico para minimizar o sofrimento gerado pelo longo período de desemprego.

Em um segundo momento, buscou-se articular essas experiências dos participantes com outras estratégias apresentadas através de boletins informativos e outros recursos (elaborados por nossa equipe) que abordavam temas como, por exemplo: trabalho autônomo, cooperativismo, formação de redes interpessoais e redes de desenvolvimento local, microcrédito, políticas públicas de emprego e trabalho. $\mathrm{O}$ acesso às informações apresentadas 
pelos boletins permitiu o acréscimo de referências importantes para tecerem futuros projetos, possibilitando o contato com outras formas de trabalho, o que foi um aspecto valorizado por vários dos participantes.

\section{Sexto encontro - saberes e conhecimentos construídos no percurso de trabalho}

No sexto encontro discutiram-se os saberes não reconhecidos - aqui definidos como experiências, conhecimentos e habilidades desenvolvidos ao longo da vida e nas atividades desempenhadas no trabalho e que não eram reconhecidas no mercado formal de trabalho. A retomada da trajetória profissional estimula a reflexão sobre os conhecimentos desenvolvidos, o que pode permitir o reconhecimento desses saberes e contribuir para a elaboração de projetos profissionais futuros.

Neste encontro solicitou-se aos participantes que fizessem uma reflexão sobre os limites e as possibilidades de um caminho profissional, considerando os modos de fazer e os saberes relativos às diferentes atividades já realizadas por eles em seu percurso de vida e de trabalho. Esse exercício permitiu ressignificar o currículo e os possíveis planos e intenções futuras de trabalho, levando em consideração limites, conflitos e especificidades do atual mundo do trabalho, como será exemplificado em seguida.

Rever os saberes individualmente nem sempre é possível. Alguns dos participantes já estavam há muito tempo desempregados e, por essa razão, sentiam-se desqualificados, incompetentes e impotentes. Nesse contexto, a troca e a discussão em grupo puderam por vezes propiciar a passagem de um lugar daquele que nada sabe para o daquele que também tem saberes construídos ao longo de sua vida, a partir, inclusive, do reconhecimento pelos outros participantes sobre esses saberes.

Especialmente nos encontros iniciais, eram comuns frases como "eu não sei o que fazer" ou silêncios constantes frente a perguntas como: "o que você sabe fazer?" ou "que tipos de trabalho você conhece?". Ao longo do processo, porém, outros relatos foram aparecendo, em que foi possível ao grupo e ao próprio participante vislumbrar em detalhes, por exemplo, quais saberes eram necessários às várias atividades que haviam feito.

Nesse momento, houve uma grande variedade de relatos, como: saber cozinhar ou plantar; saber realizar obras, pintar casas, montar peças (de metalurgia ou eletrônicas); saber formas de ensinar outras pessoas; conhecer processos de trabalho em gráficas; saber e gostar de trabalhar junto com outras pessoas; conhecer certas formas de organização de um negócio próprio; conhecer planejamento de empresas; saber realizar pesquisas e buscas de informações; saber realizar atividades de secretária e de vendas. Trouxeram ainda outros conhecimentos construídos em seu cotidiano, como: ajudar pessoas, realizar atividades artesanais, dançar, conhecer trabalhos corporais (como massagem), fazer biscoitos, jogar futebol, nadar.

Em um grupo formado em sua maioria por homens, foi possível perceber um viés de gênero na separação entre os saberes provenientes do espaço do trabalho e os saberes construídos em outros espaços sociais. As atividades de planejamento e organização em empresas ou o trabalho operário eram marcas do mundo do trabalho para esses homens. Já as atividades corporais, artesanais e de ajuda eram realizadas por eles no tempo livre, não como trabalho. Foi também possível perceber uma diferença de classe em relação aos tipos de trabalhos realizados, qual seja, a divisão entre trabalho manual e trabalho intelectual, expressa especialmente entre o trabalho como operário e o trabalho feito por quem tinha cursado faculdade. No caso das mulheres, que tinham terceiro grau completo, havia uma marca tanto de classe, como de gênero: realizaram, em empresas, atividades de planejamento na área de alimentos ou de vendas. 
A partir desses relatos, ao final do encontro, solicitou-se aos participantes o desenho de possíveis projetos de trabalho para serem discutidos no próximo encontro.

\section{Sétimo encontro - discussão de projetos e atividades possíveis de geração de renda e trabalho}

Para finalizar, a sistematização das intenções e dos projetos trazidos pelos participantes ao longo dos encontros anteriores contribuiu para o desenho de um projeto de trabalho que considerou, dentro do possível, diferentes prazos de realização (curto, médio e longo prazos).

A prática do registro das discussões ao longo dos encontros, como apontado anteriormente, possibilitou nesse momento a apresentação da síntese das discussões feitas. Os participantes discutiram a respeito dos esboços de seus projeto, enfatizando as estratégias que permitiriam viabilizá-los e as limitações que poderiam encontrar nesse percurso.

Os participantes trouxeram propostas de projetos (alguns considerando diferentes etapas, outros considerando o que seria mais imediato e urgente), identificaram formas de viabilizá-los e apresentaram como dificuldades: falta de assistência às pessoas em situação de desemprego, especialmente as de renda baixa; medo do fracasso e da humilhação frente às recorrentes tentativas que tiveram ao longo de seu percurso como desempregados.

Sobre o que vislumbravam como possibilidades de projetos, alguns preferiram continuar na busca por empregos, mas considerando quais as informações necessárias para tanto e como utilizar o currículo como estratégia de apresentação em certos processos seletivos; alguns queriam rever os tipos de trabalhos que buscavam e ampliar a procura por outros tipos trabalhos no mercado formal através dos conhecimentos que afinal possuíam; alguns queriam tentar possibilidades de gerar renda no mercado informal.

Um dos participantes decidiu mapear e acessar trabalhos no chamado "terceiro setor"; outro decidiu manter a procura de trabalho no setor público como estratégia para ter um trabalho fixo e, depois disso, buscar um trabalho que fosse mais afinado com o que gostava; um deles, ainda, decidiu manter a busca por emprego e, caso se empregasse, ensaiaria em seu tempo livre atividades que contemplassem aquilo que gostava de fazer como hobby, para depois se dedicar a essas mesmas atividades como um trabalho.

Cabe pontuar ainda que nesse encontro foi feita uma avaliação do conjunto dos encontros e das propostas do projeto. Essa avaliação funcionou como uma espécie de síntese final do projeto e circunstanciou aquilo que foi proposto inicialmente e o que foi efetivamente realizado.

Durante o processo do grupo, dos dez participantes iniciais, três deixaram de ir aos encontros. Desses, dois avisaram ter conseguido um emprego nesse meio tempo e um não pôde ser localizado. Acreditamos que um dos motivos da saída deste último participante pode ter sido o fato de ter considerado o projeto apenas um paliativo para o seu problema, e não uma saída concreta, questão trazida reiteradamente pelo participante nos primeiros encontros.

Entre os participantes que permaneceram até o final do grupo, destacou-se em comum a importância conferida a um espaço de conversa em grupo, de troca e de desabafo com outras pessoas a respeito do desemprego e das situações cotidianas que vêm enfrentando desde que ficaram desempregados. Além disso, salientaram a importância de se olhar de outro modo para a própria trajetória de trabalho e para os saberes que possuem.

Alguns participantes falaram ainda da relevância de existir um momento em que se estabelecia para eles um compromisso semanal, o que lhes dava um norte ao longo da semana 
em relação tanto à reflexões importantes que gostariam de compartilhar com os outros no encontro seguinte, quanto às ações que consideravam necessárias realizar entre um encontro e outro. Assim, o grupo funcionou para alguns como um certo organizador de seu cotidiano e, o que lhes propiciava construir outro sentido para seu dia-a-dia. Já outros participantes ressaltaram a necessidade de um maior direcionamento dos encontros através de "dinâmicas" (como exercícios para saber se o participante possui liderança etc.).

Desse modo, o grupo assumiu para os participantes que permaneceram ao longo dos encontros tanto um necessário lugar de acolhimento e de troca de experiências e informações, quanto um espaço incompleto em que seria necessário se encontrar uma resposta mais certeira e objetiva para enfrentarem o desemprego. É nessa linha tênue que o projeto parece se constituir para os que dele participaram nesse grupo.

Essas são, porém, reflexões preliminares sobre um projeto que ainda está em fase inicial e que merecem ser destrinchadas cuidadosamente. Neste momento, contudo, optou-se por fazê-lo de modo breve, apontando-se certas questões e compreensões dele depreendidas.

\section{Considerações finais}

Dos temas abordados ao longo dos encontros foi possível depreender certos aspectos que deram contorno ao grupo realizado. Nesse grupo ficou nítida a sua importância como suporte social, seja pelo acolhimento dos sofrimentos vividos, seja pela de troca de experiências entre os participantes, seja como lugar de reconhecimento de si e de outros, seja como espaço para produção de certos conhecimentos, seja como local de acesso às informações. Esse acesso toma relevo ainda maior em uma organização social que se pauta, por um lado, pela fragmentação e pulverização de certas informações e, por outro, pela centralização de várias informações relevantes por certos grupos sociais como forma de manutenção de poder e desigualdade social (Castells, 1999).

Tomaram relevo também o rememorar e o ressignificar a trajetória de trabalho e a própria história desses participantes, especialmente se for considerado que fazem parte de uma sociedade que se apresenta fortemente marcada por ações e representações que buscam retirar de certos grupos sociais sua historicidade e suas formas de pertencimento ao mundo (Benjamin, 1991).

Destacou-se ainda a possibilidade de os participantes reverem posicionamentos através da interlocução com outros que vivem a mesma situação e de se problematizar ideários que atrelam o desemprego a uma falta ou culpa individual, retomando os aspectos políticos, sociais e históricos do desemprego (Chaui, 2001; Forrester, 1997; Neves, 2002; Neves et al., 1998).

Por outro lado, também permearam o grupo a existência e, por vezes, a permanência de certos preconceitos e estigmas sociais em relação a alguns aspectos do mundo do trabalho, como, por exemplo, os olhares que comumente se tem em relação aos chamados trabalhadores informais (Dias, 2002). Além disso, houve por parte de alguns, como anteriormente apontado, a expectativa de que propostas como o projeto aqui analisado revelassem uma saída concreta para o desemprego vivido, junto com um pedido retomado no final dos encontros de que o projeto deveria ter exercícios mais diretivos para tanto, o que caracteriza em parte alguns projetos de combate ao desemprego propostos atualmente por certas organizações sociais e por determinadas políticas públicas.

Para finalizar este artigo, optou-se por enumerar questões que circunscrevem e limitam a proposta de atuação com pessoas desempregadas. Um aspecto relevante refere-se 
ao fato desta ser uma experiência que abre algumas possibilidades de reflexão e de ação em relação ao desemprego. Como já foi dito, é necessário também considerar especificidades locais e características dos grupos sociais com os quais se pretende realizar um projeto deste tipo.

Em relação à formação de grupos com pessoas desempregadas, é preciso salientar que se trata de uma forma de minimizar os impactos do desemprego, sem, porém, ter-se a pretensão de, através da intervenção em grupo, solucionar a dimensão estrutural do desemprego. Para tanto seria necessário, dentre outros aspectos, mudanças macro-estruturais.

O desafio foi constituir uma proposta de atuação que articulasse essas concepções sobre o desemprego estrutural e o mundo do trabalho sem recairmos em formas de culpabilização das pessoas que estão desempregadas nem tampouco, como alerta Souza (2000, p. 248), eliminar os aspectos políticos atrelados a essas questões.

Acredita-se, desse modo, que uma ação pontual com grupos de pessoas desempregadas é apenas uma forma de diminuir o impacto do desemprego sobre a vida dessas pessoas. Sua importância, se empreendida isoladamente, é a de constituir momentos de ajuda e de encontro com outras pessoas que vivem cotidianamente essa situação e como espaço de reconhecimento e de troca para ressignificação, construção, reconstrução ou reflexão sobre as formas possíveis, nesse contexto, de geração de renda e busca de trabalho. Tal projeto situase e constitui-se nas brechas existentes em nossa sociedade para formas, mesmo que efêmeras ou precárias, de resistência e de ruptura, seja de modo coletivo, seja de modo individual.

Destaca-se, porém, a relevância da articulação de projetos como este com outros suportes e redes sociais que visam construir modos de enfrentamento ao desemprego para que as atuações realizadas em tais projetos não sejam isoladas e pouco eficazes. Desta proposta, depreende-se, por outro lado, a pertinência de que, nessa articulação, considerem-se as trajetórias de vida e de trabalho das pessoas desempregadas e os conhecimentos construídos por elas a partir de suas experiências cotidianas.

\section{Referências}

Ackermann, K., Amaral, M. A., Silva, J. C. B., Geraldes, A. L., Lima, T. N., Lombardi Júnior, M., Mendes, A. \& Scandiucci, G. (2005). O desemprego do tempo: narrativas de trabalhadores desempregados em diferentes ambientes sociais. Cadernos de Psicologia Social do Trabalho. 8, 1-27.

Alves, G. (2000). O novo (e precário) mundo do trabalho: reestruturação produtiva e crise do sindicalismo. São Paulo: Boitempo.

Antunes, R. (2001). Os sentidos do trabalho: ensaio sobre a afirmação e a negação do trabalho. São Paulo: Boitempo.

Arendt, H. (2000). A condição humana. Rio de Janeiro: Forense Universitária.

Azevedo, J. T., Bogre, M. C., Bombardi, V. M., Chen, M. C., Mampo, E. Y., Martins, A. N., Moraes, A. L., Silva, Ana P. O. \& Silva, M. de F. N. (1998). As estratégias de sobrevivência e de busca de emprego adotadas pelos desempregados. Cadernos de Psicologia Social do Trabalho. 1, 15-42.

Batista, N. C. S. (2005). Pegando fila... contando um pouco da cotidianeidade do trabalhador desempregado na cidade de São Paulo. Dissertação de Mestrado, Programa de Estudos Pós-Graduados em Psicologia Social, Pontifícia Universidade Católica de São Paulo, São Paulo.

Benjamin, W. (1991). Teses sobre a filosofia da história. In F. R. Khote (Org.), Walter Benjamin (pp. 153-164). São Paulo: Ática.

Berger, P. \& Luckmann, T. (1985). A construção social da realidade. Petrópolis: Vozes. 
Bordieu, P. (1994). O campo científico. In R. Ortiz (Org.), Pierre Bourdieu (pp. 123-155). São Paulo: Ática.

Bourdieu, P. (1997). Compreender. In P. Bordieu (Org.), A miséria do mundo. Petrópolis: Vozes.

Bosi, E. (2003). Memória e sociedade: lembrança dos velhos (10ª ed.). São Paulo: Companhia das Letras.

Bruschini, C. \& Lombardi, M. R. (2003). Mulheres e homens no mercado de trabalho brasileiro: um retrato dos anos 1990. In M. Maruani \& H. Hirata (Orgs.), As novas fronteiras da desigualdade: homens e mulheres no mercado de trabalho (pp. 323-356). São Paulo: Senac.

Cacciamali, M. C. (2000). Globalização e processo de informalidade. Economia e Sociedade, 14, $153-174$

Castel, R. (1999). As metamorfoses da questão social: uma crônica do salário. Petrópolis: Vozes.

Castells, M. (1999). A era da informação: economia, sociedade e cultura. São Paulo: Paz e Terra.

Certeau, M. (1999). A invenção do cotidiano: artes de fazer. Petrópolis: Vozes.

Chaui, Marilena. (2001). Brasil: mito fundador e sociedade autoritária (4⿳亠口冖 reimpressão). São Paulo: Perseu Abramo.

Centro de Psicologia Aplicada ao Trabalho (2005). Relatório de atividades de 2005. [digitado]

Cunha, J. M. P. \& Dedecca, C. S. (2000). Migração e trabalho na região metropolitana de São Paulo. Revista Brasileira de Estudos da População, 17 (1/2), 97-118.

Dias, A. R. (2002). Condições de vida, trajetórias e modos de "estar" e "ser" catador: estudo de trabalhadores que exercem atividade de coleta e venda de materiais recicláveis na cidade de Curitiba (PR). Dissertação de Mestrado, Instituto de Psicologia, Universidade de São Paulo, São Paulo.

Forrester, V. (1997). O Horror Econômico. São Paulo: Edunesp.

Guimarães, E. V. (2003). Executivos em revista: discursos de e para executivos e aspirantes a executivos. Dissertação de Mestrado, Instituto de Psicologia, Universidade de São Paulo, São Paulo.

Guimarães, N. A. \& Hirata, H. (Orgs.). (2006). Desemprego: trajetórias, identidades, mobilizações. São Paulo: Senac.

Guimarães, N. A. (2005). Transições ocupacionais e representações sobre a procura de trabalho comparando mercados de trabalho sob diferentes regimes de welfare: São Paulo, Paris y Tóquio. Revista Galega de Economia, 14 (1/2), 1-25.

Jinkings, N. (1995). O mister de fazer dinheiro: automatização e subjetividade no trabalho bancário. São Paulo: Boitempo.

Heller, A. (2000). O Cotidiano e a história. Rio de Janeiro: Paz e Terra.

Jahoda, M. (1987). Empleo y desempleo: un análisis socio-psicológico. Madri: Ediciones Morata.

Lautier, B. \& Pereira, J. L. (1994). Representações sociais e construção do mercado de trabalho: empregadas domésticas e operários da construção civil na América Latina. Cadernos CRH, 21, $125-151$.

Mandelbaum, B. (2004). O desemprego em situação: esboços de estruturação de uma clínica social. Tese de Doutorado, Instituto de Psicologia, Universidade de São Paulo, São Paulo.

Marcuse, Herbert (1997). Cultura e sociedade (vol. 1). Rio de Janeiro: Paz e Terra.

Marques, C. J. (1996, 14 de fevereiro). O Brasil desempregado. Isto é (pp. 22-25).

Mattoso, J. E. (1994). Trabalho sob fogo cruzado. São Paulo em Perspectiva, 8 (1), 13-21.

Ministério do Planejamento (1997). Cadernos MARE da Reforma do Estado (1 e 2). Brasília: Ministério do Planejamento.

Montagner, P. \& Haga, A. (2003). Pesquisa de emprego e desemprego: sua importância como metodologia de pesquisa. São Paulo em Perspectiva, 17 (3/4), 135-141. 
Neves, T. F. S., Ortega, C. de A., Barreto, R. A., Kim, C., Muller, E., Costa, F. B., Massola, G. M., Dadico, L., Barros, L. H., Lopes, P. S., Amêndola, M. F. \& Pires, T. A. A. (1998). Desemprego e ideologia: as explicações das causas do desemprego utilizadas por trabalhadores metalúrgicos. Cadernos de Psicologia Social do Trabalho, 1, 1-13.

Neves, T. F. S. (2002). Vítimas ou culpados? O fio da navalha... In H. Cavalcanti \& J. Burity (Orgs.), 1․ Seminário Internacional Polifonia da miséria: uma construção de novos olhares (pp. 71-84). Recife: Massangana.

Neves, T. F. S. (2006). Ensaios sobre o desemprego: qualidades de um "novo" trabalhador? Imaginário, $13,123-142$.

Nunes, J. A. (2002). Teoria crítica, cultura e ciência. $\mathrm{O}(\mathrm{s})$ espaço(s) e o(s) conhecimento(s) da globalização. In B. de S. Santos (Org.), A globalização e as ciências sociais (2ae-ed.). São Paulo: Cortez.

Oliveira, R. C. (2000). O trabalho do antropólogo (2ª ed.). São Paulo: Unesp.

Pochmann, M. (1997). Políticas de emprego e renda no Brasil. In L. Bogus \& A. Paulino (Orgs.), Políticas de emprego, políticas de população e direitos sociais. São Paulo: Educ.

Pochmann, M. (Org.). (2003). Outra cidade é possível: alternativas de inclusão social em São Paulo. São Paulo: Cortez.

Pochmann, M., Pereira, M., Barbosa, A., Silva, R., Amorin, R., Benedito, M., Oliveira, M., Scalco, T., Conte, V., Guerra, A. \& Pereira, M. A. (2006). Classe Média: desenvolvimento e crise. São Paulo: Cortez.

Prefeitura Municipal de São Paulo (2004). Mulheres em São Paulo: um perfil da cidade. São Paulo: Coordenadoria Especial da Mulher.

Salvitti, A., Viégas, L. de S., Mortada, S. P. \& Tavares, D. S. (1999). O trabalho do camelô: trajetória profissional e cotidiano. Cadernos de Psicologia Social do Trabalho, 2, 1-23.

Santos, B. de S. (1999). Pela mão de Alice: o social e o político na pós modernidade. São Paulo: Cortez.

Sato, L. \& Schmidt, M. L. S. (2004). Psicologia do trabalho e psicologia clínica: um ensaio de articulação focalizando o desemprego. Estudos de Psicologia, 9 (2), 365-371.

Schmidt, M. L. S. (1995). O passado, o mundo do outro e o outro do mundo: tradição oral e memória coletiva. Imaginário, 2, 89-100.

Seligmann-Silva, E. (1997). A interface desemprego prolongado e saúde psicossocial. In J. F. Silva Filho \& S. Jardim (Orgs.), A danação do trabalho: organização do trabalho e sofrimento psíquico. Rio de Janeiro: Te Corá.

Singer, P. (1998). Globalização e desemprego: diagnóstico e alternativas. São Paulo: Contexto.

Singer, P. (2002). Introdução à economia solidária. São Paulo: Perseu Abramo.

Singer, P. \& Souza, A. R. de (Orgs.). (2000). A economia solidária no Brasil: a autogestão como resposta ao desemprego. São Paulo: Contexto.

Souza, A. R. de (2000). Os empreendimentos comunitários de São Paulo. In P. Singer \& A. R. de Souza (Orgs.), A economia solidária no Brasil: a autogestão como resposta ao desemprego. São Paulo: Contexto.

Souza, A. R. de, Cunha, G. C. \& Dakuzaku, R. Y. (Orgs.). (2003). Uma outra economia é possível: Paul Singer e a economia solidária. São Paulo: Contexto.

\section{Endereço para correspondência}

anete@usp.br, taneves@usp.br

Recebido em: 28/09/2006

Revisado em: 10/04/2007

Aprovado em: 14/07/2007 